\title{
GAZODUC Les Marches de l'Est, tronçon 3
}

Pré-le-Maire, site 3, un établissement gallo-romain

Jean-Jacques Thévenard

\section{(2) OpenEdition}

Édition électronique

URL : http://journals.openedition.org/adlfi/9157

ISSN : 2114-0502

Éditeur

Ministère de la culture

Référence électronique

Jean-Jacques Thévenard, « GAZODUC Les Marches de l'Est, tronçon 3 », ADLFI. Archéologie de la

France - Informations [En ligne], Lorraine, mis en ligne le 01 mars 2001, consulté le 19 avril 2019. URL :

http://journals.openedition.org/adlfi/9157

Ce document a été généré automatiquement le 19 avril 2019.

(c) Ministère de la Culture et de la Communication, CNRS 


\title{
GAZODUC Les Marches de l'Est, tronçon 3
}

\author{
Pré-le-Maire, site 3, un établissement gallo-romain
}

Jean-Jacques Thévenard

\author{
Identifiant de l'opération archéologique : F1388200105510 \\ Date de l'opération : 2001 (PT)
}

1 Les investigations archéologiques menées préalablement à la mise en place du gazoduc sur le territoire de Vaux-la-Grande, lieu-dit Pré-le-Maire, ont révélé un site à vocation rurale du Haut-Empire. Les vestiges semblent se rattacher à une villa mais dans l'état actuel de nos connaissances, nous ne pouvons pas localiser le corps de logis principal qui se situe à l'extérieur de l'emprise du projet.

Deux types de constructions ont été reconnus. Le premier type est renseigné par la cave maçonnée St. 7 ; le second est élaboré à partir d'une armature de pièces de bois enfoncées dans le sol dont on ne retrouve plus aujourd'hui que les fosses d'implantation (avanttrous).

3 Les autres indices d'occupation relevant de cette phase sont constitués d'un fossé, de fosses et de petits creusements assimilables à des trous de poteau mais qui n'ont pu être rattachés à un plan de bâtiment ou d'aménagement définissable.

D'un point de vue chronologique, les études céramique et numismatique permettent de retenir l'hypothèse d'une occupation du site depuis la première moitié du $\mathrm{I}^{\mathrm{er}}$ siècle de notre ère jusqu'à la fin du $\mathrm{II}^{\mathrm{e}} \mathrm{s}$., voire la première moitié $d u \mathrm{III}^{\mathrm{e}} \mathrm{s}$.

THÉVENARD Jean-Jacques 
INDEX

operation Prospection thématique (PRT)

Index géographique : Lorraine, Meuse (55), Saulvaux

Index chronologique : Empire romain, Haut-Empire

Thèmes : cave, céramique gallo-romaine, édifice, fosse, fossé, habitat rural, numismatique, occupation du sol, trou de poteau, villa

\section{AUTEURS}

JEAN-JACQUES THÉVENARD

AFAN 